\title{
Processos educativos desvelados na roda de capoeira da Associação Pena de Ouro
}

\author{
Educational processes unveiled in the capoeira circle of the Pena de Ouro Association
}

Procesos educativos desvelados en la rueda de capoeira de la Asociación Pena de Ouro

\author{
GILMAR ARAUJO de OLIVEIRA ${ }^{1}$; LUIZ GONÇALVES JUNIOR ${ }^{2}$; FÁBIO RICARDO MIZUNO \\ LEMOS $^{3}$ \\ Universidade Federal de São Carlos, UFSCAR, SÃo CARLos-SP, BraSIL \\ InStituto Federal de São Paulo, IFSP, São Carlos-SP, Brasil
}

\begin{abstract}
RESUMO
O objetivo deste estudo ${ }^{4}$ foi identificar, descrever e compreender os processos educativos desencadeados na relação Mestre-Aprendiz no contexto dos treinos de Capoeira da Associação Cultural e Desportiva Pena de Ouro, ministradas pelo Mestre Izael Teixeira. Nos orientamos pela Fenomenologia e, em busca de uma compreensão do fenômeno, realizamos inserção na citada Associação, localizada no município de São Carlos, interior do estado de São Paulo. A coleta de dados ocorreu entre outubro de 2014 e maio de 2015, totalizando 15 encontros, com 11 participantes. Durante todos os encontros foram redigidos registros sistemáticos de observações em diários de campo, dos quais foram organizadas as seguintes categorias temáticas: A) Pedagógica de Mestre Izael; B) Valorização do Mestre Izael pela Comunidade; C) Enquanto descanso, carrego pedra resistência e ancestralidade. Foram identificados processos educativos de resistência, ancestralidade, pertencimento e fortalecimento de identidades.
\end{abstract}

Palavras-chave: Processos Educativos. Capoeira. Cultura Popular.

\begin{abstract}
The objective of this study was to identify, describe and understand the educational processes of the MasterApprentice relationship in the training sessions of Capoeira of the Cultural and Sports Association Pena de Ouro, developed by Master Izael Teixeira. We use the Phenomenology to understand the phenomenon and we perform insertion in the Association, located in the city of São Carlos, in the interior of the state of São Paulo. Data collection took place between October 2014 and May 2015, totaling 15 meetings, with 11 participants. The observations of all the meetings were systematically recorded in field diaries, from which the thematic categories were organized: A) Pedagogical of Master Izael; B) Valorization of Master Izael by the Community; C) While resting, I carry stone - resistance and ancestry. Educational processes of resistance, ancestry, belonging and the strengthening of identities were identified.
\end{abstract}

Keywords: Educational Processes. Capoeira. Popular Culture.

\section{RESUMEN}

El objetivo de este estudio fue identificar, describir y comprender los procesos educativos desencadenados en la relación Maestro-Aprendiz en el contexto de los entrenamientos de Capoeira de la Asociación Cultural y Deportiva Pena de Ouro, impartidos por el Maestro Izael Teixeira. Nos orientamos por la Fenomenología y, en busca de una comprensión del fenómeno, realizamos inserción en la citada Asociación, ubicada en el municipio de São Carlos, interior del estado de São Paulo. La recolección de datos ocurrió entre octubre de 2014 y mayo de 2015, totalizando 15 encuentros, con 11 participantes. Durante todos los encuentros se redactaron registros sistemáticos de observaciones en diarios de campo, de los cuales se organizaron las siguientes categorías temáticas: A) Pedagogía del Maestro Izael; B) Valorización del Maestro Izael por la Comunidad; C) En cuanto descanso, llevo piedra - resistencia y ancestralidad. Se identificaron procesos educativos de resistencia, ancestralidad, pertenencia y fortalecimiento de identidades.

Palabras clave: Procesos Educativos. Capoeira. Cultura Popular.

\footnotetext{
${ }^{1}$ Doutorando em Educação na UFSCar. E-mail: araujodeoliveiragilmar@ gmail.com

${ }^{2}$ Professor Titular do Departamento de Educação Física e Motricidade Humana e do Programa de PósGraduação em Educação da UFSCar. E-mail: luiz@ufscar.br

${ }^{3}$ Professor do IFSP São Carlos. E-mail: fabio.lemos@ifsp.edu.br

${ }^{4}$ Estudo decorrente de pesquisa de mestrado que contou com fomento da Coordenação de Aperfeiçoamento de Pessoal de Nível Superior (CAPES).
} 


\title{
INTRODUÇÃOO
}

Ao participar de uma prática social, dentro de um grupo, comunidade, instituição, associação, as pessoas se apropriam de valores ali edificados e compartilhados, conhecimentos construídos, tradições que são construídas e/ou preservadas naquele ambiente, também lidam com os conflitos decorrentes daquela prática, assim como a resolução de eventuais problemas.

Segundo Oliveira et al. (2014):

Práticas sociais decorrem de e geram interações entre os indivíduos e entre eles e os ambientes [...] em que vivem. Desenvolvem-se no interior de grupos, de instituições, com o propósito de produzir bens, transmitir valores, significados, ensinar a viver e a controlar o viver, enfim, manter a sobrevivência material e simbólica das sociedades humanas (p.33).

E acrescentamos, concordando com Sousa (2009):

\begin{abstract}
Ao participarem de diferentes práticas sociais, as pessoas se apropriam de valores e comportamentos de seu tempo e lugar e lutam por sua existência. Em suas interações, as pessoas expõem seus modos de ser e perceber o mundo, elas desenvolvem e transmitem estratégias para solucionar os problemas que lhe desafiam em seu cotidiano. São distintos os objetivos das práticas sociais, dessa forma, elas podem tanto enraizar e manter vivas as tradições, valores e postura de certo grupo, como podem desenraizar, negando a cultura de determinado povo. $\mathrm{O}$ tráfico de pessoas africanas para as Américas foi uma prática de desenraizamento, em contrapartida, a capoeira praticada por africanos ao chegarem aqui no Brasil, pode ser entendida como uma prática que levava ao enraizamento, pois se configurou como uma manifestação de resistência à violência que essas pessoas eram submetidas (p. 4).
\end{abstract}

A Capoeira é uma manifestação de africanos/as e afro-brasileiros/as construída no Brasil como resistência e luta destes povos ao processo de escravização. Todavia, sua origem, segundo Gonçalves Junior (2009), ainda é muito discutida decorrente da escassa documentação a respeito da escravização no Brasil, pois Rui Barbosa, então Ministro da Fazenda no primeiro governo republicano do Brasil, exercido por Deodoro da Fonseca, através da Resolução de 15/11/1890, dá a ordem de queima de documentos que atestavam a escravidão, alegando que esta era uma mancha que deveria ser apagada da história do país. Sabe-se, no entanto, que o interesse era prioritariamente econômico, já que fazendeiros, donos dos escravos (considerados se-moventes, na legislação do período) exigiriam indenizações pelo fim da escravidão.

Para Sodré (2002) e Abib (2005), o importante não é o começo, a data histórica, mas é o princípio, questões que a geraram e que a mantém em expansão. Consideram que a Capoeira é uma criação de africanos/as em solo brasileiro a partir de danças rituais como o N'Golo (dança da zebra). Abib (2005) declara que no caso da Capoeira, a historicidade e o começo são brasileiros, mas o princípio e o fundamento são africanos.

Neste sentido, já havia contribuído Rego (1968), ao afirmar que:

No caso da capoeira, tudo leva a crer que seja uma invenção dos africanos no Brasil, desenvolvida por seus descendentes afro-brasileiros, tendo em vista uma série de fatores colhidos em documentos escritos e sobretudo no convívio e diálogo constante com capoeiras atuais e antigos que ainda vivem 
na Bahia, embora, em sua grande maioria, não pratiquem mais a capoeira (p. $31)$.

Assim, a prática social da Capoeira revelou-se contra a violenta opressão daqueles/as, sobretudo europeus, que escravizavam e desumanizavam os/as africanos/as, enquanto estes/as lutavam e resistiam protagonizando sua própria história. Sendo que Memmi (1989) denominou este período de colonização das Américas e escravização de africanos/as e seus/suas descendentes, bem como indígenas, como um dos mais tristes e dolorosos períodos da história da humanidade.

Enquanto protagonistas de suas histórias, os/as negros/as foram forjando sua cultura a qual entendemos enquanto popular, concordando com Dussel (1982), que "[...] a cultura popular é, essencialmente, a noção chave na 'pedagógica da libertação'; somente ela é fundamento do pro-jeto de libertação, pro-jeto eticamente justo, humano, alterativo" (p. 214).

Prossegue Dussel (1982, p. 225): “[...] a cultura popular é o ponto mais incontaminado e irradiativo da resistência do oprimido [...] contra o opressor, constituindo-se no momento mais autêntico da cultura de um povo", no qual ele faz parte, como protagonista, desse processo de criação e recriação.

Para Dussel (1982, p. 225):

Esta criação cultural se exprime historicamente por uma arte popular (que não é o "rústico", mas que também inclui o artesanal), especialmente a música que exprime rítmica e faladamente a história, os sofrimentos e as gestas do povo; é uma língua própria, com suas estruturas, modismos, usanças; [...] é uma tradição em seu sentimento autêntico; são os símbolos que exprimem pletoricamente o projeto e as mediações na existência do povo; são símbolos religiosos [...]; são símbolos políticos pelos quais o povo recorda (é sua história não escrita) suas lutas, seus heróis, seus traidores, seus amigos, seus inimigos [...]. Enfim, é uma totalidade de sentido humano.

Fiori (1991) escreve que o ser "[...] só é verdadeiramente pessoa enquanto dono do seu destino [...]. Não se trata, apenas, de escolher; trata-se de dominar-se e realizarse - não só de liberdade inicial, mas liberdade de autonomia" (p. 237), ou seja, de seu fazer histórico.

Freire (2011) acrescenta:

\begin{abstract}
Humanização e desumanização, dentro da história, num contexto real, concreto, objetivo, são possibilidades dos homens como seres inconclusos e conscientes de sua inconclusão. Mas, se ambas são possibilidades, só a primeira nos parece ser o que chamamos de vocação dos homens. Vocação negada, mas também afirmada na própria negação. Vocação negada na injustiça, na exploração, na opressão, na violência dos opressores. Mas afirmada no anseio de liberdade, de justiça, de luta dos oprimidos, pela recuperação de sua humanidade roubada (p. 40).
\end{abstract}

Vale destacar que o Brasil foi um dos últimos países do mundo a proibir a comercialização e o uso de mão de obra escrava, em 1888. Mesmo depois da Proclamação da República, em 1889, práticas culturais africanas e afro-brasileiras continuaram sendo perseguidas e criminalizadas, tais como, o Candomblé e a Capoeira. Veja-se que o decreto $\mathrm{n}^{\circ} 487$ do Código Penal da República dos Estados Unidos do Brasil, de 11 de outubro de 1890, no capítulo XIII, que tratava dos "Vadios e Capoeiras", previa: 


\begin{abstract}
Art.402 - Fazer nas ruas e praças públicas exercícios de agilidade e destreza corporal, conhecidos pela denominação de capoeiragem, andar em correrias, com armas ou instrumentos capazes de produzir uma lesão corporal, provocando tumulto ou desordens, ameaçando pessoa certa ou incerta, ou incutindo temor ou algum mal: Pena de prisão celular de dois a seis meses. Parágrafo Único - É considerada circunstância agravante pertencer o capoeira a algum bando ou malta. Aos chefes ou cabeças se imporá a pena em dobro.

Art.403 - No caso de reincidência será aplicada ao capoeira, no grau máximo, a pena de um a três anos, a colônias penais que se fundarem em ilhas marítimas, ou nas fronteiras do território nacional, podendo para esse fim ser aproveitados os presídios militares existentes.

Art.404 - Se nesses exercícios de capoeiragem perpetrar homicídio, praticar alguma lesão corporal, ultrajar o pudor público e particular, perturbar a ordem, a tranquilidade ou segurança pública ou for encontrado com armas, incorrerá cumulativamente nas penas combinadas para tais crimes (citado por REGO, 1968).
\end{abstract}

Somente na década de 1930, Getúlio Vargas, buscando o apoio das massas populares legaliza o voto feminino, do analfabeto e do soldado, além de extinguir a proibição de cultos afro-brasileiros e da prática da Capoeira (GONÇALVES JUNIOR, 2009).

Para Lima (1990), Vargas objetivava a integração e homogeneidade do país e atendeu algumas reivindicações dos/as trabalhadores/as, liberando uma série de manifestações populares, entre elas a Capoeira, restringindo-a, no entanto, a recintos fechados, criando uma forma de controle sobre a mesma.

Neste contexto, conforme Gonçalves Junior (2009), em 1937, o governo Vargas formaliza o ensino da Capoeira e concede, a Manoel dos Reis Machado, o Mestre Bimba (1899-1974), o alvará do Centro de Cultura Física Regional, em Salvador Bahia. Bimba criou sistematização de seu ensino com oito sequências de golpes e contragolpes realizadas em duplas objetivando melhor fixação dos movimentos. Estabeleceu assim, a luta regional baiana, posteriormente denominada de Capoeira Regional.

Ainda em acordo com Gonçalves Junior (2009), em contraposição à Capoeira Regional, Vicente Ferreira Pastinha, o Mestre Pastinha (1889-1981), organiza e funda, em 1941, o Centro Esportivo de Capoeira Angola. Visava Pastinha preservar o que julgava ser a verdadeira Capoeira, baseada na tradição africana, imbuída de ritualidade, ludicidade, teatralidade e musicalidade.

Com a constituição das escolas Regional e Angola se inicia um processo de rivalidade entre capoeiras que, em certa medida, se mantém até os dias de hoje (ABIB, 2005; GONÇALVES JUNIOR, 2009; CAMPOS, 1990; LIMA, 1990; REGO, 1968; SILVA, 1995).

Por outro lado, a Capoeira, outrora prática criminosa, desde julho de 2008, é reconhecida enquanto patrimônio cultural imaterial brasileiro (IPHAN, 2008).

Conforme Nogueira (2013) a Capoeira, enquanto uma prática social, constrói conhecimentos, repassa valores e tradições, tradições essas de matriz africana: os velhos mestres, as ladainhas cantadas, a dança, a luta, o jogo, tudo isso representa expressão da tradição oral africana, recriada no contexto brasileiro.

Em acordo com Tedla (1995) na visão de mundo africana é fundamental considerar alguns princípios, dentre eles o representado pelo adinkra sankofa, o qual faz referência a pássaro do território africano que se alimenta de sementes que caem em suas costas. O sentido metafórico está em voltar-se para trás para se alimentar, alimentando-se também da ancestralidade, retornando para a fonte e buscando o 
alimento, onde a fonte é nossa cultura, herança e identidade. Em suma, sankofa significa que para nos movermos à frente precisamos retornar ao passado buscando nossas raízes.

Ainda conforme Tedla (1995), na visão africana, as pessoas se remetem ao princípio de comunidade, de coletividade, assumindo uma relação orgânica entre os membros. Nesta perspectiva ser uma pessoa, é estar pronta para dividir, para ajudar ao próximo. Nesse sentido percebemos outro princípio da visão de mundo africana, além da ancestralidade aludido pela expressão sankofa, o princípio ubuntu, o qual, segundo Tutu (2012): "Uma pessoa é uma pessoa por intermédio de outras pessoas. [...] Ubuntu é a essência do ser humano" (p. 41-42), tal princípio alude que uma pessoa só pode atingir a humanidade associada à de outra pessoa, em comunidade (comum-unidade). Continua Tutu (2012), que diferentemente do "Penso, logo existo" eurocêntrico de Descartes, na perspectiva africana "Existo porque pertenço": preciso de outros seres humanos para ser. "Posso ser eu só porque nós somos, pois somos feitos para a complementaridade. Somos criados para uma rede delicada de relacionamentos, de interdependência com os nossos companheiros seres humanos, com o restante da criação" (p. 42).

Portanto, a Capoeira como uma prática social nos leva a conhecer um pouco da história e cultura do povo africano e de seus descendentes no Brasil, a luta do/a negro/a por expressar sua filosofia, seu modo de viver, sua liberdade, sua humanidade e sua corporeidade.

Diante disso, buscamos nesta pesquisa, identificar, descrever e compreender os processos educativos desencadeados na relação Mestre-Aprendiz no contexto dos treinos de Capoeira da Associação Cultural e Desportiva Pena de Ouro, ministrados pelo Mestre Izael Teixeira.

Em acordo com Gonçalves Junior, Carmo e Corrêa (2015), compreendemos que processos educativos:

[...] ocorrem em uma relação mútua de aprendizagem e não só em uma situação em que um ensina ao outro, tendo como pressuposto fundamental para seu desenvolvimento o diálogo equitativo e a intencionalidade dirigida para a cooperação, superação, o ser mais, demandando autonomia, possibilidade de decisão e de transformação. Tais condições permitem aos envolvidos compreender em contexto, valores e códigos do grupo, da comunidade e da sociedade em que vivem, tendo a possibilidade de refletir criticamente sobre sua própria condição de pertencimento ao mundo com os outros, educando e educando-se (p. 176-177).

\section{TRAJETÓRIA METODOLÓGICA}

Para a realização desta pesquisa nos orientamos pela Fenomenologia, entendendoa como o estudo das essências e voltada à compreensão das experiências vividas pelos sujeitos face aos fenômenos, na procura do contato originário com outrem ao mundo em intersubjetividade (MERLEAU-PONTY, 1996).

Segundo Machado (1994):

A preocupação central desta trajetória de pesquisa se dá com o ato de compreender, mais do que explicar o objeto de estudo. A fenomenologia significando discurso esclarecedor a respeito daquilo que se mostra por si mesmo, enquanto uma práxis ou forma de ação, opera através do método que investiga a experiência, no sentido de compreendê-la e não de explicá-la. Compreender diz respeito a uma forma de cognição que diverge da explicação. Compreender é tomar o objeto a ser investigado na sua intenção 
total, é ver o modo peculiar específico do objeto existir. Explicá-lo é tomá-lo na sua relação causal (p. 35).

Em busca desta compreensão, realizamos inserção na Associação Cultural e Desportiva Pena de Ouro, localizada no município de São Carlos, interior do estado de São Paulo. A coleta de dados foi autorizada pelo Mestre Izael, pelos/as participantes dos treinos de Capoeira e Comitê de Ética e Pesquisa com Seres Humanos (Parecer $\mathrm{n}^{\circ}$ 1.237.621), observando-se o uso de nomes fictícios escolhidos pelos/as próprios/as colaboradores/as. A inserção ocorreu entre outubro de 2014 e maio de 2015, totalizando 15 encontros. O grupo de inserção foi escolhido por: a) pertencer à Associação de Capoeira mais antiga e em funcionamento da cidade de São Carlos, possuindo mais de 30 anos, inclusive no mesmo local; b) ter o maior número de participantes ( 7 homens e 4 mulheres) treinando no mesmo horário; c) serem todos/as considerados/as pelo Mestre como iniciantes ou intermediários.

Durante todos os encontros foram redigidos registros sistemáticos de observações em diários de campo, que, segundo Bogdan e Biklen (1994) “[...] é o relato escrito daquilo que o investigador ouve, vê, experiencia e pensa no decurso da recolha e reflectindo sobre os dados de um estudo qualitativo" (p. 150).

Após diversas leituras dos registros do diário de campo, ao percebermos unidades de significado, estas foram agrupadas em categorias temáticas, objetivando movimento intencional em busca da essência do fenômeno pesquisado (BICUDO; ESPÓSITO, 1994; MARTINS; BICUDO, 2005).

Salientamos que os diários de campo analisados são representados pelos algarismos romanos I, II, III etc., seguidos de números arábicos, após hífen, indicando a respectiva unidade de significado. Assim, "IV-2" significa que o excerto apresentado diz respeito ao: "diário de campo quatro, unidade de significado dois".

\section{CONSTRUÇÃO DOS RESULTADOS}

Durante a análise de dados emergiram três categorias:

\section{A) PedagógiCa de Mestre IZael}

A pedagógica de Mestre Izael, consiste na forte relação mestre-discípulo. Segundo Dussel (1982, p.153) "[...] a pedagógica não deve ser confundida com a pedagogia, que é a ciência do ensinamento ou aprendizagem". Para ele:

A pedagógica ao contrário, é a parte da filosofia que pensa a relação face-aface do pai-filho, mestre-discípulo, médico-psicólogo-doente, filósofo-nãofilósofo, político-cidadão etc. Ou seja, o pedagógico neste caso tem uma ampla significação de todo tipo de "disciplina" (o que recebe de outro) em oposição à "invenção" (o que se descobre por si mesmo) (DUSSEL, 1982, p. 154).

Percebemos esta relação nos diálogos entre o Mestre Izael e seus/suas discípulos/as: o respeito ao tempo de aprendizagem de cada um/a, a forma próxima de conduzir sua aula:

Enquanto aquecíamos ele tocava o berimbau em uma cadência muito bonita, tocando Idalina, Banguela, São Bento Grande, Cavalaria. E enquanto tocava todos nós fazíamos a ginga conforme o ritmo e vez ou outra o Mestre parava o berimbau para nos orientar como fazer a ginga e às vezes pedia para alguém tocar o berimbau enquanto auxiliava os/as demais aprendizes. Logo 
em seguida [...] ao toque chamado Idalina (toque de berimbau criado por Mestre Bimba), pediu a todos/as que entrassem na roda para gingar, às vezes em duplas, às vezes em trios e ele mesmo participando desses trios. [...] colocou a Maria para tocar o berimbau, ao perceber que ela não conseguiria tocar, por não saber o toque, disse a ela que fizesse o toque que soubesse que não teria problemas e logo em seguida disse a Maria que não tivesse medo, que ficasse à vontade para tocar assim ela ganhava confiança e também aprenderia os toques. Logo depois a turma foi dividida em duplas, cada dupla com um treino específico, Cappota e Siri faziam a primeira sequência de Mestre Bimba, Maria e Hulk também [...], enquanto a Fernanda fazia os primeiros movimentos, mais básicos. [...] Em alguns momentos parava a todos para explicar um ou outro movimento (I-1).

Nesta relação, podemos perceber a existência do cuidado do Mestre com seus/suas discípulos/as, em preservar a integridade, individualidade e o limite de cada um/a:

Fomos treinando até a terceira sequência do Mestre Bimba, Cappota e Siri, com o Mestre observando de perto e interrompendo vez ou outra para corrigir e dar atenção ao Hulk. Em um dado momento o Mestre notou que o Cappota havia se cansado, então pediu para que ele se sentasse, enquanto Pedro e Siri continuavam o treinamento. O Mestre Izael e o Cappota sentaram-se em um banco bem próximo à roda, ficaram conversando e ao olhar nosso treino o Mestre reparou a dificuldade de Siri em esquivar para o lado esquerdo, pois o Pedro quase acertou o nariz dele com uma benção. Então ele parou o treino nesse momento e falou sobre a dificuldade de Siri e o que ele deveria fazer para melhorar, mostrando vários exercícios. Percebemos que o Mestre deu muita atenção e demonstrou preocupação com os/as alunos/as (V-3).

$\mathrm{Na}$ pedagógica de Mestre Izael ele mantém os elementos da cultura popular presentes na Capoeira no decorrer das aulas, tentando assim não perder suas características, sofrer alterações na sua raiz. Na unidade de significado a seguir Mestre Izael estimula seus/suas discípulos/as a gingarem conforme o ritmo de cada toque de berimbau tocado por ele, frequentemente perguntando aos/às participantes o nome do toque e os/as deixando curiosos/as sobre como afinar adequadamente o berimbau.

O Mestre Izael armava um de seus berimbaus nos dizendo como o som daquele berimbau era bom! [...] Explicou que o segredo está no modo de afinar o instrumento e o ajuste da cabaça, e sorrindo nos disse que um dia nos ensinaria. [...] Segundo ele, devemos obedecer ao ritmo do berimbau, gingar balançando o corpo, sem acelerar e nem diminuir o ritmo. Fez vários toques de berimbau da Capoeira Regional, sempre parando e explicando o modo de gingar em cada um deles. Também entre um toque e outro dizia não se lembrar qual o nome de determinado toque, nos perguntando se sabíamos, apenas o Cappota arriscava responder, o Pedro se manteve apenas sorrindo e dizendo que não sabia, o Cappota disse que também não sabia, mas que chutaria uma resposta e assim o fez, não acertando o toque. [...] Quando Mestre Izael perguntou ao Siri, ele disse que achava ser o toque de Amazonas e o Mestre prontamente o questionou: acha ou é? Siri confirmou que era o toque de Amazonas (II-2).

A pedagógica de Mestre Izael preserva valores pertencentes à cultura popular e incentiva a todos/as a se apropriarem desta cultura. E nesta relação, Mestre e Discípulo/a vão se formando, aprendendo e ensinando, também por vezes organizava situações em que participantes com mais experiência (no caso desta turma, medianos/as na prática da Capoeira, com tempo superior a 1 ano e igual ou inferior a 3 anos) com os/as alunos/as menos experientes (no caso desta turma, iniciantes na prática da 
Capoeira, com tempo igual ou inferior a 1 ano), conforme anotações do Diário de Campo X, unidade de significado 1.

\title{
B) VALORIZAÇÃo DO MESTRE IZAEL PELA COMUNIDADE
}

Nesta categoria, observamos o respeito e a valorização pela comunidade do trabalho desenvolvido pelo Mestre Izael. O papel de Mestre de Capoeira está atrelado a uma liderança na comunidade onde atua.

Câmara (2004) afirma:

O Mestre de capoeira possui sabedoria que não é apenas da técnica de jogo, mas também da experiência de vida, é respeitado por toda a comunidade onde ensina, possuí sabedoria que advém da experiência e humildade. Seus aprendizes o tratam como alguém que possui a capacidade de ajudá-los no aprendizado da capoeira (p. 51).

O apreço pelo Mestre Izael é constante conforme registros de observações em diários de campo, quando membros da comunidade, por exemplo, passam na Associação para conversar com ele, quando ex-alunos/as levam seus filhos/as para fazer aulas com o Mestre, conforme segue: "Várias pessoas passaram pela Associação, algumas para se informar sobre aulas de Capoeira, outras para falar com o Mestre, mães que trazem seus filhos cujo pai já treinou com o Mestre há muito tempo atrás" (I-2).

Ainda no tocante aos ex-alunos/as, além de levarem seus/suas filhos/as para praticar Capoeira com o Mestre Izael, mantêm um vínculo muito forte com ele e mesmo morando em outras cidades, sempre encontram uma maneira de passar pela Associação para visitá-lo, conversar, treinar:

\begin{abstract}
Andorinha, uma ex-aluna do Mestre que agora mora em outra cidade, perguntou a Siri a partir de que horas ele estaria na Associação, pois gostaria de treinar e queria companhia. [...] Nesse dia o treino se iniciou no meio da conversa mesmo, de uma forma mais espontânea, estávamos todos por ali e entre uma conversa e outra o Mestre pediu para que formássemos duplas e começássemos a gingar para aquecer (IV-1).
\end{abstract}

Os vínculos de afeto e amizade criados nas relações entre Mestres e Discípulos/as podem durar por toda a vida, é mútuo. Nessas relações são construídos processos educativos de respeito e de reconhecimento, indo além da mera movimentação física dos golpes, defesas e contragolpes.

Abib (2006) destaca:

O Mestre, na cultura popular em geral, adquire esse reconhecimento por ter se notabilizado perante a sua comunidade, em razão de sua capacidade de ser ele um transmissor dos saberes de seus antepassados. Esse processo na cultura bantu, reveste-se de importância capital, pois essa cultura põe em estreita relação os antepassados e seus descendentes, convencidos antes que não poderiam perpetuar sua linhagem sem a proteção dos antepassados (p. 95).

Prossegue Abib (2006): "Os mestres exercem um papel central na preservação e transmissão dos saberes que organizam a vida social no âmbito da cultura popular, caracterizando, assim, a oralidade como forma privilegiada dessa transmissão" (p. 91).

Estas relações que envolvem processos educativos de atenção e cuidado de uns/umas com outrem, contribuem para a formação para a vida dos/as alunos/as. Como vemos, o Mestre de Capoeira, Mestre da cultura popular, mantém uma estreita relação 
com a comunidade onde desenvolve seu trabalho, agindo na formação de muitas pessoas ao longo do tempo, para além do objeto específico de ensino, no caso desta pesquisa a Capoeira, compartilhando lições de vida, inclusive pela corporeidade do exemplo, o que também está imbricado na categoria a seguir.

\section{C) ENQUANTO DESCANSO, CARREGO PEDRA - RESISTÊNCIA E ANCESTRALIDADE}

A Capoeira, que já foi considerada prática criminosa, proibida por lei no Brasil, hoje patrimônio cultural brasileiro, envolve luta constante de seus/suas Mestres.

Nesse movimento de luta, que conforme metaforicamente afirmou Mestre Izael, em um dos treinos de nossa inserção: "enquanto descanso, carrego pedra", amparado pela ancestralidade, pela constante resistência e afirmação/re-afirmação de suas raízes africanas, os/as Mestres também lutam com todo tipo de adversidades, dentre elas a financeira, conforme segue:

Cappota e Siri ao final do treino se despediram do Mestre e saíram da Associação, na calçada Cappota comentou ao Siri que Izael é uma pessoa boa e de profundo conhecimento, tanto com relação à Capoeira como nas coisas da vida, modo de viver e se relacionar com todos/as, não entendia como passava por dificuldades financeiras, ainda precisando acumular outras funções para sobreviver, como roçar terrenos (IV-2).

Porém, o amor pela Capoeira, que no caso de Mestre Izael se confunde com o próprio existir dele, o mantém praticando e ensinando há mais de trinta anos no mesmo local, conforme relato:

O Mestre parou o treino uns minutos antes do fim, pediu para que ficássemos em roda, pegou um pandeiro e como faltava uma semana para comemoração dos trinta anos da Associação Pena de Ouro, informou que não haveria aula na próxima semana, pois estaria com muitos afazeres para organizar o evento [...]. Disse aparentemente emocionado o que era comemorar trinta anos da Associação no mesmo lugar, enfrentando dificuldades e resistindo a todas as adversidades, mas que fazia pelo o amor à Capoeira. Agradeceu por estarmos ali com ele e também disse que a nossa presença seria muito importante no evento e como sempre diz: vamos aprender juntos (III-2).

A ancestralidade envolve também preservação das tradições, do modo de aprender e ensinar, no caso da Capoeira. No fragmento de diário de campo a seguir, registramos o cuidado de Mestre Izael com os preceitos preconizados por Mestre Bimba, fundador da escola de Capoeira denominada Regional.

Demos início ao aquecimento com ginga, cocorinha, negativa, esquiva lateral, esquiva lateral com rolê, au e au de rolê, em seguida as sequências de Mestre Bimba. Após todos/as terem feito até a terceira e quarta sequência, mais ou menos, o Mestre parou o treino, armou um berimbau e pediu para que todos/as se dispusessem na roda. Explicou que tocaria um pouco para todos/as jogarem, com exceção de Hulk que estava iniciando os treinos naquele dia, então Mestre Izael pediu para que ele ficasse na roda observando. Mestre Izael também pediu para todos/as que durante os jogos, utilizassem os movimentos aprendidos com a prática das sequências. Todos/as tiveram a oportunidade de jogar pelo menos umas duas vezes antes do final da roda (XIII-1).

Esta ancestralidade e resistência são afirmadas todas as vezes que Mestre Izael para e se refere a Mestre Bimba e outros Mestres de Capoeira com os quais teve contato 
direto ou indireto, nos instigando com perguntas, ou contando histórias, que vão desde o modo de guardar os berimbaus até o modo de viver:

Terminado sua demonstração, veio pegar o berimbau que estava nas mãos de Siri e perguntou: "De que modo se guardavam os berimbaus na academia do Mestre Bimba"? Todos/as disseram não saber, ele então perguntou novamente, Siri explicou a ele que nas academias de Capoeira Regional os berimbaus são guardados com a cabaça para o lado de cima. Mestre Izael disse que estava correta a resposta, pois Mestre Deputado, Mestre de Mestre Izael na Capoeira Regional, lhe explicou que a cabaça é a cabeça do berimbau e que por isso deve ser mantida para cima (II-3).

Através da oralidade, a lembrança dos Mestres antigos sempre se faz presente nos treinos de Capoeira do Mestre Izael, o que representa um elemento de valorização da filosofia africana, a experiência dos mais velhos através das histórias contadas, das ladainhas e dos toques de berimbau. "Nesse dia, o Mestre tocou o Apanha a Laranja no Chão Tico-Tico. Assim que ele terminou todos/as bateram palmas e se cumprimentam. Mestre Izael sempre nos diz para bater palma bem forte, segundo ele, Mestre Bimba sempre fazia o mesmo" (II-6).

As histórias contadas fortalecem a todos/as, a referência aos antigos mestres são processos educativos, como apontado por Câmara (2004):

Como se vê, a oralidade é elemento importante ao transmitir a memória [...]. A comunidade negra a partir de histórias, músicas e cantos, na África e no Brasil, utiliza a linguagem oral como instrumento da tradição, repassando aos seus descendentes valores próprios a este grupo humano. É no cantar que também se expressa o conhecimento. Neste sentido, na cosmovisão africana a experiência não se dá de maneira fragmentada, dissociando os elementos da cultura, mas sim pela vivência integrada do cotidiano construindo e reelaborando significados (p. 40).

\section{CONSIDERAÇÕES}

Consideramos que um destacado processo educativo observado foi resistência. Mestre Izael resiste, apesar de todas as adversidades, dentre as quais a financeira, ensinando Capoeira, cerca de trinta anos no mesmo local (que também é a residência dele), como ele mesmo costuma enfatizar: sua vida se pauta "por amor à Capoeira".

Esta resistência é a própria luta do povo negro no Brasil para manter viva suas raízes, conforme corrobora Gonçalves Junior (2009):

Luta do povo africano e afro-brasileiro em busca de liberdade e afirmação de sua corporeidade, luta esta que não se deu (dá) apenas na movimentação física, mas na motricidade, ou seja, no movimento intencional de transcendência, portanto, do ser no contexto do mundo (p. 2).

E neste movimento de resistência, a busca por valorização desta prática social que tem muito a nos ensinar sobre modos de educar e educar-se, podendo incluir nos sistemas escolares outras filosofias ou epistemologias, tais como os princípios africanos Sankofa e Ubuntu, respectivamente apresentados por Tedla (1995) e Tutu (2012).

Estudos anteriores com Capoeira, como de Câmara (2004), Abib (2005), Gonçalves Junior (2009) e Nogueira (2013), consideram fundamental o trabalho com 
Capoeira para a educação das relações étnico-raciais, afirmação de identidade, combate ao racismo, resistência ideológica a um modelo cultural dominante (eurocêntrico), além de outras possibilidades de ensino e de aprendizagem oriundos da cultura popular, os quais favorecem processos educativos de conhecimento e reconhecimento da: sabedoria dos/as mais velhos/as (ancestralidade); de outras formas de comunicação para além da escrita, como a oralidade; e de outras formas de ser e estar ao mundo, ou seja, fortalecimento de outras identidades.

\begin{abstract}
Sentir/perceber/apreender a diversidade cultural pela vivência em grupo, respeitando a si mesmo e ao outro, seus saberes e experiências, pode despertar um novo olhar de si e do outro e facilitar a afirmação de identidades, com orgulho de suas origens, neste caso africanas, e respeito e reconhecimento destas por pessoas de outras origens, as quais devem ter suas raízes étnico culturais igualmente respeitadas e reconhecidas (GONÇALVES JUNIOR, 2009, p. 7).
\end{abstract}

Neste estudo, consideramos também que as lições do Mestre Izael vão além do objeto de ensino, a Capoeira, mas possibilitam ou abrem-se à formação para a vida, ao "tornar-se pessoa" (SILVA, 2003).

Câmara (2004) afirma que a Capoeira pode configurar-se "[...] enquanto um processo educativo de perpetuação de valores e crenças da comunidade afrodescendente, na tentativa não apenas de se libertar da marginalização e das discriminações, mas também de afirmar uma identidade afrodescendente" (p. 9).

Como vimos, a ancestralidade se fez presente nos treinos do Mestre Izael, que frequentemente rememorava junto aos/às alunos/as os Mestres antigos e seus respectivos ensinamentos.

Também o modo de Mestre Izael organizar os treinos preserva valores pertencentes à cultura popular e afro-brasileira despertando em seus/suas alunos/as a riqueza existente nesta, confirmando suas raízes originárias e contribuindo para a libertação cultural, visto que "[...] fomos pedagogicamente educados na desvalorização de nossa cultura popular própria" (DUSSEL, 1982, p. 264). Assim, consideramos a necessidade das instituições escolares buscarem referências em trabalhos com Mestres da cultura popular, como o trabalho desenvolvido pelo Mestre Izael, pois "[...] uma libertação cultural, como processo futuro, tem que apoiar-se na cultura do povo" (DUSSEL, 1982, p. 269).

Consideramos ainda que os resultados desta pesquisa poderão favorecer o trabalho pedagógico com Capoeira, trazendo subsídios a discussões na área de Educação, Educação Física, com repercussões em práticas escolares.

Abib (2005) reforça que a educação escolar ainda carece de uma visão ampliada de referenciais provenientes da cultura popular, africana e afro-brasileira, sendo fundamental tais referenciais para minimizar a visão preconceituosa e folclorizada de manifestações como a Capoeira.

Esse conhecimento é indispensável para que não se descaracterize os modos de vida próprios da cultura afro-brasileira, folclorizando práticas sociais, tais como, a da própria Capoeira.

A constante busca e atualização dos conhecimentos acerca da história do povo africano e afro-brasileiro junto a seus protagonistas, movimento negro, mestres da cultura popular, grupos de manifestações culturais de matriz africana, são fundamentais para o conhecimento e reconhecimento das lutas por liberdade, defesa de direitos, resistência ao branqueamento de sua cultura, recomposição de sua corporeidade. 


\section{REFERÊNCIAS}

ABIB, P. R. J. Os velhos capoeiras ensinam pegando na mão. Cadernos Cedes, v. 26, n. 68, p. 86-98, jan./abr. 2006.

ABIB, P. R. J. Capoeira Angola: cultura popular e o jogo dos saberes na roda. Campinas: UNICAMP/CMU; Salvador: EDUFBA, 2005.

BICUDO, M. A. V.; ESPOSITO, V. H. C. (Orgs.). Pesquisa qualitativa em educação: um enfoque fenomenológico. Piracicaba: UNIMEP, 1994.

BOGDAN, R.; BIKLEN, S. Investigação qualitativa em educação: uma introdução à teoria e aos métodos. Porto: Porto Editora, 1994.

CÂMARA, E. Capoeira Angola: uma contribuição à prática do professor no reconhecimento e valorização da comunidade afro-descendente. 2004. 131 f. Dissertação (Mestrado em Educação) - Centro de Educação e Ciências Humanas, Universidade Federal de São Carlos, São Carlos, 2004.

CAMPOS, H. Capoeira regional: a escola de Mestre Bimba. Salvador: EDUFBA, 2009.

CAMPOS, H. Capoeira na escola. Salvador: Presscolor, 1990.

DUSSEL, E. Para uma ética da libertação latino-americana III: erótica e pedagógica. Piracicaba: UNIMEP, 1982.

FIORI, E. M. Textos escolhidos: educação e política. Porto Alegre: L\&PM, 1991.

FREIRE, P. Pedagogia do oprimido. 50. ed. Rio de Janeiro: Paz e Terra, 2011.

GONÇALVES JUNIOR, L. Dialogando sobre a capoeira: possibilidades de intervenção a partir da motricidade humana. Motriz, v. 15, n. 3, p. 700-707, 2009.

GONÇALVES JUNIOR, L.; CARMO, C. S.; CORRÊA, D. A. Cicloviagem, lazer e educação ambiental: processos educativos vivenciados na Serra da Canastra. Licere, v. 18, n. 4, p. 173-208, 2015.

IPHAN registra capoeira como patrimônio cultural brasileiro. Folha Online, 15 jul. 2008. Disponível em: <http://www1.folha.uol.com.br/folha/cotidiano/ult95u422731.shtml >. Acesso em: 01 out. 2018.

LIMA, L. A. N. A capoeira: um discurso em extinção. São Paulo: PUCSP/FAPESP, 1990.

MACHADO, O. V. M. Pesquisa qualitativa: modalidade fenômeno situado. In: BICUDO, M. A. V.; ESPOSITO, V. H. C. (Orgs.). Pesquisa qualitativa em educação: um enfoque fenomenológico. Piracicaba: UNIMEP, 1994. p. 35-46.

MARTINS, J.; BICUDO, M. A. V. A pesquisa qualitativa em psicologia: fundamentos e recursos básicos. São Paulo: Centauro, 2005.

MEMMI, A. Retrato do colonizado precedido pelo retrato do colonizador. 3. ed. Rio de Janeiro: Paz e Terra, 1989.

MERLEAU-PONTY, M. Fenomenologia da percepção. 2. ed. São Paulo: Martins Fontes, 1996.

NOGUEIRA, S. G. Psicologia crítica africana e descolonização da vida na prática da capoeira Angola. 2013. 226 f. Tese (Doutorado em Psicologia Social) - Pontifícia Universidade Católica São Paulo, São Paulo, 2013.

OLIVEIRA, M. W.; SILVA, P. B. G.; GONÇALVES JUNIOR, L.; MONTRONE, A. V. G.; JOLY, I. Z. L. Processos educativos em práticas sociais: reflexões teóricas e metodológicas sobre pesquisas em espaços sociais. In: OLIVEIRA, M. W.; SOUSA, F. R. (Orgs.). Processos educativos em práticas sociais: pesquisas em educação. São Carlos: EdUFSCar, 2014. p. 29-46. 
REGO, W. Capoeira Angola: um ensaio sócio-etnográfico. Salvador: Itapoã, 1968.

SILVA, G. O. Capoeira: do engenho à universidade. 2. ed. São Paulo: CEPEUSP, 1995.

SILVA, P. B. G. Aprender a conduzir a própria vida: dimensões do educar-se entre afrodescendentes e africanos. In: BARBOSA, L. M. A.; SILVA, P. B. G.; SILVÉRIO, V. R. (Orgs.). De preto a afrodescendente: trajetos de pesquisa sobre relações étnico-raciais no Brasil. São Carlos: EdUFSCar, 2003. p. 181-197.

SODRÉ, M. Mestre Bimba: corpo de mandinga. Rio de Janeiro: Manati, 2002.

SOUSA, F. R. Sentidos e processos educativos consolidados na organização de uma festa popular. Políticas Educativas, v.3, n. 1, p. 79-95, 2009.

TEDLA, E. Sankofa: african thought and education. New York: Petter Lang, 1995.

TUTU, D. Ubuntu: sobre a natureza da comunidade humana. In: TUTU, D. Deus não é cristão e outras provocações. Rio de Janeiro: Thomas Nelson Brasil, 2012. p. 41-44.

Recebido em: 02 out. 2018.

Aprovado em: 11 dez. 2018. 